and not infrequently malignant changes, unfortunately so common in Britain, are extraordinarily rare.

Are hereditary, climatic, or even skin pigmentation factors involved? Despite its radiological and histological identification, is the disease process one and the same thing in different racial groups or in different places? Surely an international demographical survey is needed. It well may indicate the aetiological factor or factors in a disease which remains "of cause unknown" and which has been shown to be as prevalent and serious in Britain and elsewhere as it is strangely rare in many parts of Africa.

A T MATHESON

Wynberg,

Cape Province,

South Africa

\section{Diet and coronary heart disease}

SIR,-I am grateful for Dr V M Hawthorne's reply (16 July, $p$ 186) to my intentionally challenging letter (4 June, $p$ 1467). He confirms my view that many epidemiologists, ignoring evidence from clinical and laboratory investigators, wish through the media to persuade the public to change their diet.

Epidemiological evidence is by definition restricted, and statistical correlations are not necessarily causal. Any view of coronary disease which is based on one type of study and which omits appreciation of the whole collateral range of meticulous research is incomplete and therefore biased.

The speculation that elevated blood lipids cause atheroma is now regarded as untenable by many distinguished investigators of long experience in this field. ${ }^{1}$ Thus informed modern medical opinion is swinging away from the lipid hypothesis of causation and is unlikely, on present evidence, to condone the imposition on the public of any major change in the nature of the fats they consume.

J MCMICHAEL

London

${ }^{1}$ McMichael, J, European fournal of Cardiology. In press.

\section{Abdominal wound dehiscence}

SIR,-A number of letters and articles have recently appeared in your and other journals on the subject of the cause of the "burst abdomen." For some inexplicable reason most authors seem deliberately to avoid the allimportant factor-the nature of the incision which caused the burst abdomen.

I think everyone now accepts the evidence that transverse and oblique abdominal incisions heal better than vertical ones, and yet vertical incisions are still persistently used in operations that could just as easily be performed through incisions that are so much less likely to cause subsequent trouble. I recently reviewed a series of 400 cholecystectomies that had been performed on my unit. An oblique subcostal incision had been used routinely. There was one burst abdomen, which followed a very extensive haematoma of the abdominal wall, and this patient subsequently developed an incisional hernia. The only other burst abdomen, also followed by an incisional hernia, occurred in a patient in whom a perforated gall bladder was removed through a paramedian incision as a result of a faulty preoperative diagnosis. If only vertical incisions were avoided whenever possible I am quite sure that the incidence of both wound dehiscence and incisional hernia would almos disappear, regardless of the type of suture material employed.

Ashford Hospital,
Ashford, Middx

ROBIN BURKITT

\section{How dangerous is obesity?}

SIR,-Dr John Womersley draws attention (9 July, p 119) to the confusion which exists about the effects of obesity on health. Lack of exercise is accepted as an adverse factor in relation to coronary heart disease, and it is perhaps logical to consider obesity in relation to exercise.

The person who is mildly overweight will continue his normal way of life, expending more energy in the process; a further degree of obesity will slow him down. Thus a man who is 2 stones $(13 \mathrm{~kg})$ over Metropolitan Life Insurance Company ideal weight will probably still walk to work and climb the stairs when he gets there. In doing so he is exercising more vigorously than the man of "ideal" weight. When he reaches 4 stones $(25 \mathrm{~kg}$ ) above ideal weight he will be more likely to ride to work and to use the lift when he gets there. Thus the conclusion reached by the Chicago People's Gas Company Study" that "moderate overweight appears to be a sign of good health" is not surprising.

J J HobBs

\section{Ashington}

Ashington,

Dyer, A R, et al, fournal of Chronic Diseases, 1975, 28, 109 .

\section{Campylobacter enteritis}

SIR,-Dr M B Skirrow has reported the possible importance of campylobacters as a cause of enteritis ( 2 July, $p$ 9). During a threemonth period from the end of March 1977 we have examined 338 faecal specimens for campylobacters using the methods described by Dr Skirrow. Of these, 182 were from cases of sporadic diarrhoea, 60 from persons being screened prior to work in the food industry, 31 from convalescent carriers of intestinal pathogens, and 65 for whom no clinical details were available. The results are shown in the accompanying table.

The campylobacter isolates were kindly examined by Dr Skirrow and found to conform to the group $C$ jejuni/C coli. Two-thirds of the isolates were from patients in the age

Pathogens isolated from 338 faecal specimen

\begin{tabular}{|c|c|c|c|c|}
\hline $\begin{array}{l}\text { Category of } \\
\text { specimen }\end{array}$ & $\begin{array}{c}\text { No of } \\
\text { specimens }\end{array}$ & Pathogens isolated & No & $\%$ \\
\hline Sporadic cases of diarrhoea & 182 & $\begin{array}{l}\text { Salmonella } \mathrm{sp} \\
\text { Shigella } \mathrm{sp} \\
\text { Enteropathogenic Escherichia coli } \\
\text { Giardia } \\
\text { Campylobacter }\end{array}$ & $\begin{array}{r}1 \\
2 \\
1 \\
5 \\
14\end{array}$ & $\begin{array}{l}0.5 \\
1.1 \\
0.5 \\
2.7 \\
7 \cdot 6\end{array}$ \\
\hline $\begin{array}{l}\text { Healthy asymptomatic } \\
\text { (screening) }\end{array}$ & 60 & Campylobacter & 1 & $0 \cdot 2$ \\
\hline Convalescent carrier & 31\{ & $\begin{array}{l}\text { Salmonella sp } \\
\text { Enteropathogenic } E \text { coli }\end{array}$ & $\begin{array}{r}16 \\
1 \\
\end{array}$ & $\begin{array}{r}51 \cdot 0 \\
3 \cdot 2 \\
\end{array}$ \\
\hline $\begin{array}{l}\text { No clinical information } \\
\text { available }\end{array}$ & 65\{ & $\begin{array}{l}\text { Salmonella } \mathrm{sp} \\
\text { Shigella } \mathrm{sp}\end{array}$ & 2 & $\begin{array}{l}3.9 \\
4 \cdot 6\end{array}$ \\
\hline
\end{tabular}

range 15-44 years and the sex ratio was approximately equal.

These results, obtained from an urban area in the north-west of England, appear to confirm Dr Skirrow's observations that campylobacter is a common cause of sporadic diarrhoea in the community.

Public Health Laboratory Service B DALE Withington Hospital, Manchester

\section{Management of the elderly agitated} demented patient

SIR,-I would like to communicate some preliminary observations on the use of haloperidol in the management of the elderly agitated demented patient. Such patients present as sudden crises in the community and are a relatively common cause for the general practitioner requesting a domicilary visit by a consultant psychiatrist. Often the picture is that of an elderly relative who, despite some years of dementia, has been tolerated quite happily at home but suddenly becomes an impossible burden owing to the onset of extreme agitation. The latter, which may be due to a small but important cerebral infarct, means that the relative begins wanderthe street, and becomes very noisy and restless at night. The emotional burden on the family is sudden and intense and there is often considerable embarrassment with the neighbours. Sometimes the general practitioner has tried phenothiazines or benzodiazepine tranquillisers without success, and it is most important to prove to the family that the difficult behaviour can be controlled rapidly and effectively, as the demand for admission to non-existent psychogeriatric bed is intense and angry from the family.

Haloperidol in doses of $10 \mathrm{mg}$ thrice daily and $30 \mathrm{mg}$ at night to start with is quite safe in the old and often physically infirm. It has negligible effects upon the cardiovascular system and respiration, ${ }^{1}$ often a major hazard with phenothiazines. ${ }^{2}$ Furthermore, an analysis of such cases seen over the past two years suggests that demented patients show very much less Parkinsonian side effects than are seen in other subjects. Anti-Parkinsonian agents were rarely necessary at all, which is particularly important as the elderly seem prone to develop confusion with these drugs. A theoretical reason for this may well be the fact that recently it has been demonstrated that there is a significant reduction of choline acetylase in the neostriatum in senile dementia. This is a specific loss of cholinergic activity which is normally under tonic inhibition by ing during the day, often dangerously into 
the dopaminergic system." Thus the usual release of extrapyramidal overactivity by neuroleptics blocking dopamine receptors would be expected to occur less frequently in demented patients. In view of the considerable pressure, which is likely to increase in the future, on inadequate psychogeriatric services from an aging population the use of haloperidol should, I feel, be recommended as the drug of choice to help keep more elderly patients in the community. In 18 months, of 184 domiciliary visits, 40 were to demented patients $(22 \%)$; this reflects the seriousness of this problem in general adult psychiatric practice in a representative urban community.

Gerald Silverman

\section{St Bernard's Hospital,
Southall, Middx}

Oldham, A J, and Bott, M, Acta Psychiatrica Scandinavica, 1971, 47, 369.

2 Tobin, J M, Geriatrics, 1970, 25, 119.

3 Davies, P, and Maloney, A J F, Lancet, 1976, 2, 1403.

\section{Alcoholic liver disease}

SIR,-I have read with great interest the paper on the changing pattern of alcoholic liver disease in Great Britain by Dr N Krasner and others (11 June, p 1497).

In the district of Italy (north-east) where I work the daily average per caput alcohol consumption is very high, alcoholic liver disease is widespread, and the proportion of cirrhosis attributed to excessive drinking is greater (close to $90 \%$ ) than that reported in British surveys. ${ }^{1}$

Our experience with long-term survival rates of all patients with alcoholic liver disease in relation to continuing or stopping drinking agrees completely with the figures given by Dr Krasner and his colleagues. Indeed, alcoholic liver disease even in advanced cases seems to bear a fairly good prognosis (excluding early deaths from irreversible complications) provided that total abstinence can be achieved and indefinitely maintained.

Our findings differ from those of the authors, however, with regard to sex-related differences. In fact, while perhaps agreeing about a higher incidence of serious forms of alcoholic hepatitis in women, we do not see a significant sex-related difference in the long-term prognosis of alcoholic liver disease. Nor does our experience agree with the finding that the incidence of alcoholic hyaline on liver biopsy and of serum autoantibodies is significantly higher in women. The latter finding, indeed, is extremely uncommon in our patients (of both sexes) with alcoholic liver disease.

Although in non-alcoholic chronic hepatitis and in a few cases of alcoholic liver disease it seems undoubtedly to be so, the inference that "immune mechanisms may play a part in the pathogenesis and progression of alcoholic liver disease in women" should be accepted, in our experience, very cautiously.

Do our divergent findings reflect a genetic difference of our population or could they be related to the different type of alcoholic beverage (wine) traditionally consumed in this area?

While not quoting the serum levels of $\operatorname{IgA}$, the authors report a predominant increase in the IgM and IgG classes in women with cirrhosis, a sex-related feature we are again unable to confirm. Our finding of a higher proportional increase of $\operatorname{IgA}$ in alcoholic liver disease is confirmed by others, ${ }^{2}$ and in our experience it is so constant that we would suggest that it be regarded as an additional pointer to an alcoholic aetiology in hepatic disease.

Regional Hospital,

ANTONIO BASIL

' Basile,' A, Difesa Sociale, 1975, 3, 287.

Doniach, D, and Walker, G, in Progress in Liver Disease, eds H Popper, and F Schaffner,
p 381. New York, Grune and Stratton, 1972.

\section{Abdominal tuberculosis in Britain}

SIR,-We write to support your leading article (18 June, $p$ 1557) in which you point out that one should not be complacent that abdomina tuberculosis is a rarity in the indigenous population of Britain. You refer to our observation $^{1}$ in which 14 out of 15 patients seen in a five-year period were immigrants. However, in recent months we have seen four patients with abdominal tuberculosis, all people of English extraction and background. One was a young woman with ileocolitis and active pulmonary tuberculosis, another a teenage girl with tuberculous peritonitis, and two were middle-aged persons with small-bowel tuberculous conditions.

Clearly it is important that all clinicians managing abdominal problems be aware of the possibility of tuberculosis, whether the patient is an immigrant or otherwise.

B K MANDaL

Regional Dep

Monsall Hospital

Manchester

University Hospital of South

P F SCHOFIELD

Manchester

Mandal, B K, and Schofield, P F, Practitioner, 1976, 216, 683 .

\section{Carbon dioxide-dependent}

\section{Staphylococcus aureus from abscess}

SIR,-I am reporting this case as I have no come across any other report of isolation of such a strain from clinical materials.

A specimen of pus was sent to our laboratory from an abscess in the neck of a 31-year-old woman. Gram staining of a direct smear showed plenty of pus cells but no organism No acid-fast bacilli were seen on ZiehlNeelsen staining. Culture plates examined next day showed a pure growth on the blood agar plate incubated anaerobically but no growth on the plate incubated aerobically. The colonies looked like those of staphylococci, though were smaller in size (because of anaerobic conditions). Gram staining and coagulase testing indicated that the organism was Staphylococcus aureus.

Because of the absence of growth in aerobic conditions further tests and subcultures were done. On subculture the organism failed to grow aerobically but showed good growth anaerobically. We use BBL Gas-pak for anaerobiosis. In addition to producing anaerobiosis, this also supplies carbon dioxide. To see the effect of carbon dioxide the next subcultures were done in three conditions: (a) anaerobically with carbon dioxide, $(b)$ aerobically with carbon dioxide, and (c) aerobically without carbon dioxide. Growths were obtained in $(a)$ and $(b)$ but not in $(c)$. Colonies on (b) were larger in size than those on $(a)$. The same results were obtained on a series of sub- cultures done over several days. On further identification tests the strain was found to be coagulase positive, DNAse positive, phosphatase positive, fermentative on oxidation/ fermentation reaction, and matched well into the Cowan and Steel table ${ }^{1}$ for Staph aureus, except that it did not produce acid from mannitol. However, there are probably a few strains of Staph aureus which may not ferment mannitol, ${ }^{2}$ and no Gram-positive cocci other than Staph aureus would give positive reactions on all of coagulase, DNAse, and phosphatase tests and grow anaerobically. ${ }^{12}$

Thus it was probably a carbon dioxidedependent strain of Staph aureus, which would have been missed if we had not used Gas-pak for anaerobiosis. The organism was sensitive to all antibiotics except penicillin and tetracycline.

M RAHMAN

Department of Microbiology,

King's Mill Hospital,

Sutton in Ashfield, Notts

${ }^{1}$ Cowan, S T, Cowan and Steel's Manual for the Identification of Medical Bacteria, 2nd edn. London, Cambridge University Press, 1974.

Wilson, G S, and Miles, A A, Topley and Wilson' Principles of Bacteriology, Virology and Immunology 6th edn. London, Arnold, 1975

\section{General practitioner prescribing costs}

SIR,-In a recent leading article (12 March, p 670) you quite justifiably drew attention yet again to general practitioners' prescribing costs, at present about $£ 15000$ worth of drugs a year being handed over by each practitioner.

It was especially shocking, therefore, to hear a colleague who has recently successfully completed a vocational training course in general practice, old MRCGP and all, state blithely that drug costs "did not influence at all" his choice of medication. Further inquiry revealed that no formal instruction, nor even general guidance, in keeping prescribing costs down had been given during the three-year course. What a glorious missed opportunity for producing real economies in an overstretched NHS budget!

I wonder if this is the universal UK experience or if somewhere the GPs of the future are taught about expensive drugs and the need to use their cheaper equivalents?

ROBERT SCOTT

Craig Dunain Hospital,

Inverness

\section{Car allowance for consultants}

SIR,-Among the consultants' many grievances, one causing most resentment at present is the question of car allowances. This is particularly so among full-timers, myself included, as it has just cost me over $£ 2000$ of tax-paid income to change my modest $5 \frac{1}{2}$-yearold Austin 1800 for an equally modest Ford Cortina, for which, of course, I will receive no allowance whatsoever.

At the same time I note that general practitioner trainees have had their car allowance raised to $£ 1125$ per annum "in accordance with the agreed formula for linking the trainee car allowance to the AA's schedule of motoring costs.".

If it is right for them why not for us?
MYFR GOLDMAN 